\title{
[Review]
}

\section{REINFECTION OF CYTOMEGALOVIRUS IN RENAL TRANSPLANTATION}

\author{
KEI ISHIBASHI, OSAMU YAMAGUCHI and TATSUO SUZUTANI \\ Department of Urology, Department of Microbiology, Fukushima Medical University, Fukushima, \\ JAPAN
}

(Received February 9, 2011, accepted April 18, 2011)

\begin{abstract}
Cytomegalovirus (CMV) is the most important pathogen affecting the outcome of renal transplantation. Reinfection of CMV can occur in CMV-seropositive donors and CMV seropositive recipients $(\mathrm{D}+\mathrm{R}+)$ settings because the protection against $\mathrm{CMV}$ conferred by preexisting immunity is limited due to its strain-dependent immune responses. To analyze the influence of CMV reinfection in renal transplantation, ELISA using fusion proteins encompassing epitope of glycoprotein $\mathrm{H}(\mathrm{gH})$ from both $\mathrm{AD} 169$ and Towne strains was employed before transplantation. The CMV-gH seropositive rate increased with increases in age and the rate of samples which contained antibodies against both AD169 and Towne were significantly high in the age of 50 years or over. Antibodies from HLA-DR10 and DR11 were associated with a significantly lower response rate against $\mathrm{CMV}-\mathrm{gH}$. In renal transplantation, the high degrees of antigenemia and high incidences of CMV disease are more prevalent in the CMV gH antibody-mismatched group in $\mathrm{D}+/ \mathrm{R}+$ setting. The nucleotide sequence of the region of the $\mathrm{gH}$ epitope in the CMV-DNA extracted from the transplant recipients who showed high degree of antigenemia revealed the CMV reinfection from the donors. As a CMV indirect effect, the incidence of acute rejection in the mismatched $\mathrm{gH}$ antibody group was higher than that observed in the matched and $\mathrm{D}+/ \mathrm{R}-$ groups. The adverse events were more likely to occur in cases of $\mathrm{D}+\mathrm{R}+$ renal transplantation with mismatched strainspecific antibodies which would indicates the risk of CMV reinfection after transplantation.
\end{abstract}

Key words : cytomegalovirus, renal transplantation, glycoprotein $\mathrm{H}$, reinfection

\section{INTRODUCTION}

Renal transplantation is a most valuable treatment for patients with chronic renal failure. However, despite significant advances in the field of renal transplantation, long-term graft survival has not markedly increased ${ }^{1)}$. Among the varied reasons of this, cytomegalovirus (CMV) infection continues to be a potential contributor to graft failure, and a cause of severe mortality and morbidity. Several studies have suggested that CMV infection can lead to allograft rejection ${ }^{1-5)}$ and an episode of acute transplant rejection can lead to allograft loss and can affect the recipient's survival.

Historically, CMV serostatus influences clinical outcome in renal transplantation. The combination of CMV-seronegative transplant recipients with CMV-seropositive transplant donors $(\mathrm{D}+/ \mathrm{R}-$ ) leads to the highest risk of CMV infection. However, the analyzed data from United States Renal Data System and United Network of Organ Sharing revealed that the $\mathrm{D}+/ \mathrm{R}+$ group, not the $\mathrm{D}+/ \mathrm{R}-$, had the worst graft and patient survival by 3 years ${ }^{6,7)}$. The reason for this has not been clear. However, it may reflect the prevalence of multiple CMV virotypes and the $\mathrm{D}+/ \mathrm{R}+$ recipients may have a double CMV exposure with different CMV strain. Studies of CMV reinfection will provide clues for future strategies in prevention and treatment of CMV disease and acute rejection in renal transplantation.

石橋 啓, 山口 修, 錫谷達夫

Corresponding author : Kei Ishibashi MD, PhD E-mail address : keikun@fmu.ac.jp

http://www.jstage.jst.go.jp/browse/fms http://fmu.ac.jp/home/lib/F-igaku/ 


\section{CYTOMEGALOVIRUS VIROLOGY}

CMV, a member of the beta herpes virus family, one of the DNA viruses and is a widespread opportunistic pathogen. Primary CMV infection usually occure during the first decades of life and lead to a latent infection that can persist throughout the entire life of the host. The principal reservoirs of latent CMV are white blood cells and CD13-positive cells $^{8)}$ and the latent virus has been detected in most tissues in the body. CMV is transmitted via saliva, body fluid, cells and tissues ${ }^{9}$.

The envelope of CMV contains lipoproteins and structural proteins some of which are glycoproteins. To date, at least 57 potential glycoproteins are encoded by laboratory strain of CMV AD169 and several glycoproteins have been characterized ${ }^{10)}$. They are used for cellular entry of the virus, are the targets of virus-neutralizing antibody. Among the CMV glycoproteins, the genes encoding the glycoprotein $\mathrm{H}$ and $\mathrm{B}$ often show genetic polymorphism.

\section{Glycoprotein $H$}

Glycoprotein $\mathrm{H}(\mathrm{gH})$ is one of the immunologically dominant envelope glycoproteins of CMV. CMV$\mathrm{gH}$ has been proposed to mediate viral/host cell membrane fusion in the initial step of infectivity ${ }^{11)}$ and is essential for virus replication in cell culture $^{12)}$. Anti-CMV gH antibodies exhibit virus neutralizing activity and the $\mathrm{gH}$ is considered a major antigen for the humoral immune response ${ }^{13)}$.

There is sequence heterogeneity which was found in the first 37aa of $\mathrm{gH}$ between two laboratory strains of CMV, AD169 and Towne ${ }^{14)}$. This region is recognized by virus-neutralizing antibodies as strain-specific epitope. This heterogeneity influences CMV susceptibility to host neutralizing antibodies. A recent report on congenital CMV infection provided clear evidence that exposure to CMV with a different genotype caused congenital infection, even in seropositive mothers ${ }^{15)}$.

\section{Glycoprotein B}

Glycoprotein B (gB) is one of the most abundant envelope components. Serological responses to the $\mathrm{CMV} g B$ are detected in individuals with past CMV infection. The antigenicity of gB is well studied. Linear and conformation-dependent epitopes of neutralizing and non-neutralizing antibodies have been defined on $\mathrm{gB}^{16,17)}$. Of the epitopes, antigen domain 1 (AD1) is located between aa positions 560 and 640 of $\mathrm{gB}^{18)}$. The AD1 is one of the most highly conserved regions of $\mathrm{gB}$ and recognized as a target of virus-neutralizing antibodies.

The second antibody binding site on $\mathrm{gB}$ is the antigen domain 2 (AD2), which is located between aa 28 and 84 of $\mathrm{gB}^{16)}$. Two antibody binding sites, AD2 site I and site II, have been identified within the AD2 domain. Site I is located between aa 68 and 77 in the AD2 of the AD169 strain. This region is conserved between CMV isolates and is the target of neutralizing antibodies. Site II is located between aa 50 and 54 . Site II binds non-neutralizing antibodies and is strain specific ${ }^{16)}$.

\section{CYTOMEGALOVIRUS STRAIN- SPECIFIC SEROEPIDEMIOLOGY}

\section{Glycoprotein-specific antibody responses}

There are several reports on the rate of women positive for CMV antibodies which had usually analyzed at the time of pregnancy. According to these reports, the percentage of women who are CMV seropositive varies from $82.5 \%$ in the United States $^{19)}$, to $93.8 \%$ in Japan and $86.7 \%$ in Chile ${ }^{20)}$. It has been reported that symptomatic congenital infection is rare in the infants of women with preconceptional immunity to CMV. However, the protection conferred by preconceptional immunity is limited because of its strain-dependent immune responses ${ }^{15)}$. Reinfection can occur during organ transplantation from a donor with preexisting immunity against one strain of CMV to a recipient with antibodies against another strain, resulting in CMV transmission $^{21)}$. Thus, it is crucial to obtain information about preexisting strain-specific immunity and the glycoproteins have been used to determine preexisting strain-specific antibodies to $\mathrm{CMV}^{15,21-23)}$. The preexisting strain-specific immunity can be estimated by the presence of antibodies against glycoproteins of CMV. In our seroepidemiological analysis, which was approved by the institutional ethics committee, we employed the ELISA using GST-fusion proteins containing the strainspecific gH epitopes from AD169 and Towne strains (Figure 1) to detect strain-specific antibodies in transplant recipients. The antibodies against strainspecific gB AD2 site II epitopes and the strain-common AD2 site I epitope were also investigated. The distributions of antibody response against glycoproteins in Japan are summarized in Figure 2A. The ELISA using these fusion proteins was evaluated by a panel of sera obtained from 352 blood donors whose serostatus had been diagnosed using a conventional commercial ELISA kit. Among the 


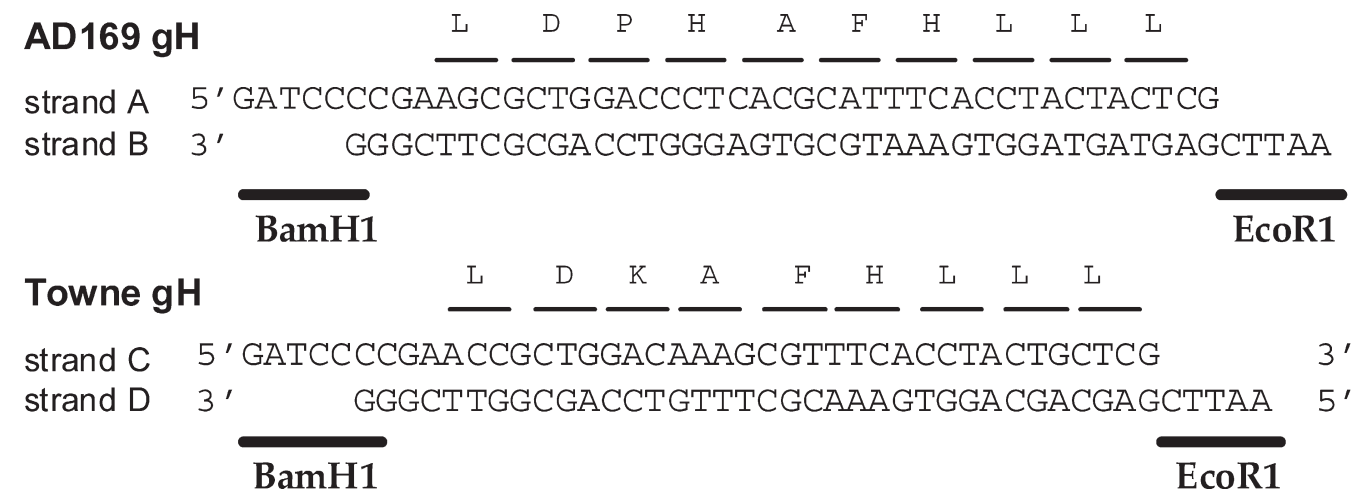

Fig. 1. Oligonucleotides containing CMV gH epitopes from AD169 and Towne strains used for the expression of gH epitopes (shown at the top of the oligonucleotides) as GST fusion proteins. Each cassette has BamHI and EcoRI sites at the ends for cloning. (Ref. 21)

A

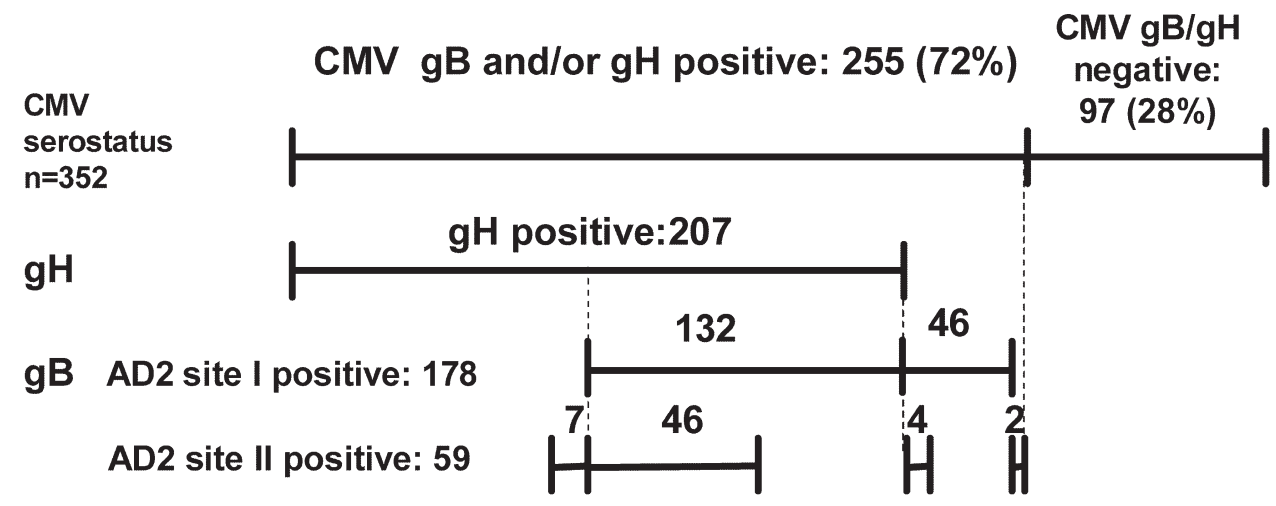

\section{B: Strain-specific responses}

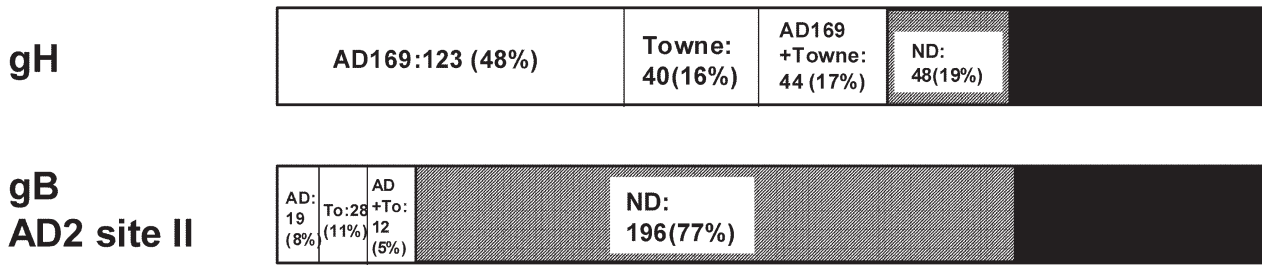

Fig. 2. A : Summary of number and distribution of samples according to antibody responses against strain-specific $\mathrm{gH}$ epitopes, and gB AD2. B : Number and percentage of samples from subjects that reacted with strain-specific antibodies against $\mathrm{gH}$ and $\mathrm{gB} \mathrm{AD} 2$ siteII. (Ref. 23)

255 serum samples with antibodies against $\mathrm{gH}$ and/ or $\mathrm{gB}, 178(69.8 \%)$ were reactive with the $\mathrm{gB} \mathrm{AD} 2$ site I ELISA and 207(81.2\%) with the gH ELISA, with 132 samples reactive with both $\mathrm{gB}$ and gH. Strain-specific antibody responses among the $207 \mathrm{gH}$ seropositive samples showed 44 samples were reactive with the $\mathrm{gH}$ of both $\mathrm{AD} 169$ and Towne (Figure 2B). Figure 3 shows the correlation between CMV serostatus and age. The CMV seropositive rate was lower in subjects aged in their teens (50\%) and 20's (62\%) than in the other age groups, and the rate increased significantly with increases in age, reaching $80-90 \%$ in subjects aged 30 years or over. Of the 44 donors whose serum contained antibodies against both AD169 and Towne, 27 (61\%) were aged 50 years or over (Figure 3 : closed columns). This dual-positive rate was significantly higher than that for donors under 50 years $(p<0.01)$. It will indicate that organ transplantation from older donors to younger recipients ; for example, from father or mother to one of their children as is common in living related transplantation, can increase the risk of reinfection with CMV.

Association between $g H$ antibodies and HLA-DR

In the age-related distribution of strain-specific 


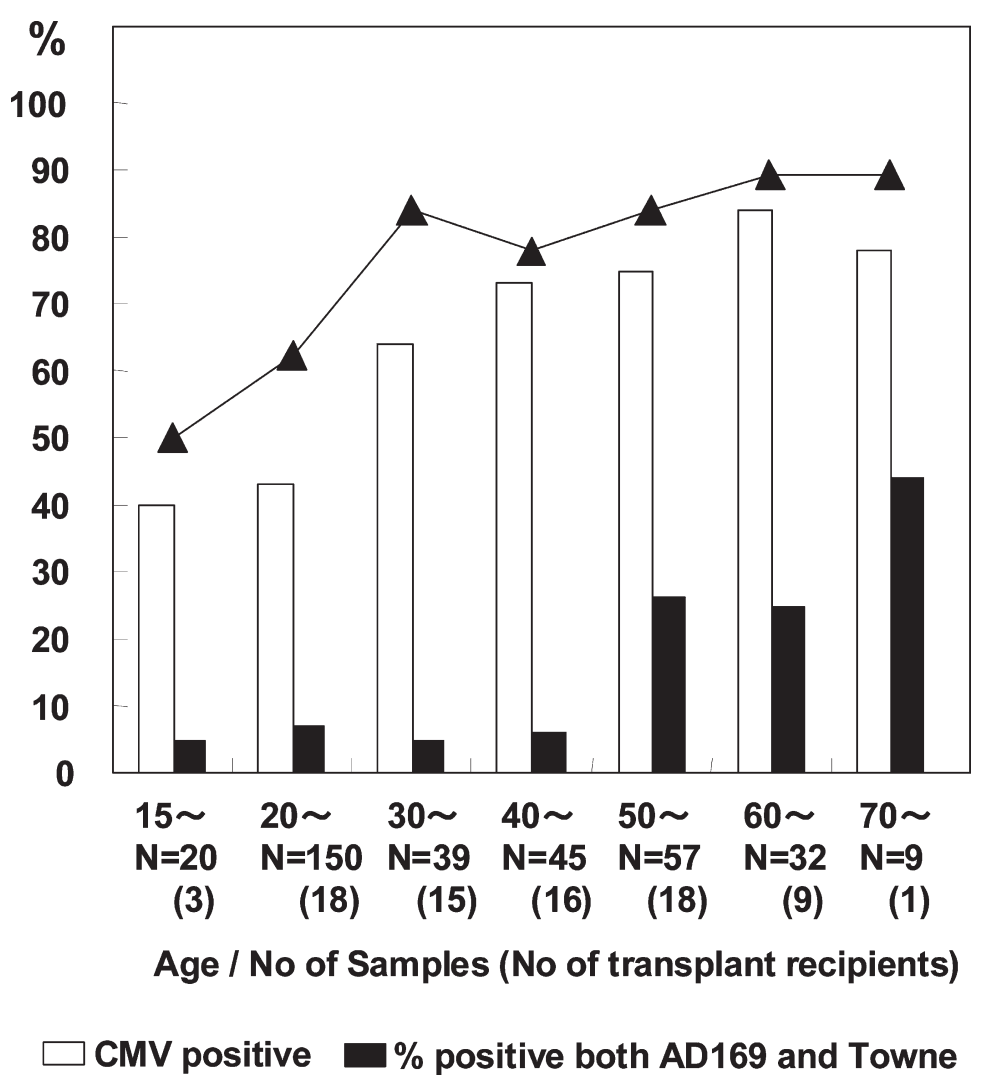

Fig. 3. Seroprevalence of CMV. Closed triangles indicate CMV seostatus analyzed using a conventional ELISA kit. Rate of positive antibodies against $\mathrm{gH}$ (open columns) and rate of positive strain-specific antibodies against both AD169 and Towne strains (closed columns) according to age. Age group and number of serum samples are shown on the holizontal axis. (Ref. 23)

antibodies against CMV gH, we found that some population of CMV-seropositive individuals did not have strain-specific gH antibodies. There reported that certain HLA alleles may be associated with antibody responses against CMV glycoprotein $\mathrm{B}^{24)}$. HLA allele distribution and positive antibodies against CMV gH ELISA in the total of 471 subjects are listed in Table $1 . \quad$ Positive rates were over 80\% in most HLA subpopulations. HLA-DR9 showed the highest positivity rate against $\mathrm{CMV} \mathrm{gH}$ ELISA, and on the contrary, HLA-DR10 and DR11 were found to be associated with a significantly lower response rate against CMV gH ELISA compared with other groups (Figure 4) ${ }^{25}$. Because immune responses against CMV are so complex, the mechanisms underlying the relationship between HLA-DR10 or DR11 and anti-CMV gH antibodies are indefinite. However, in the case of lack of strain-specific antibodies against a donor's CMV strain, CMV disease can be caused in recipients after renal transplantation ${ }^{21)}$. Besides, carriers of HLADR11 alleles are more susceptible to active CMV infection in the case of solid organ transplanta- $\operatorname{tion}^{26,27)}$. An attractive hypothesis to explain this is that organ transplant recipients with HLA-DR11 are unlikely to have strain-specific antibodies against $\mathrm{CMV}$ gH. Further studies with larger numbers are needed.

\section{INFLUENCE OF CYTOMEGALOVIRUS REINFEC- TION IN RENAL TRANSPLANTATION}

CMV infections in solid organ transplant recipients induce serious direct and indirect consequences. The direct clinical effects of CMV include CMV infection, CMV disease and end-organ diseases i.e. gastrointestinal disease, hepatitis, retinitis, nephritis, cystitis, myocarditis, pancreatitis and the like. In addition to the directly effects, CMV is associated with graft rejection, accelerated atherosclerosis, and fungal or bacterial superinfection, which are known as the "indirect effects" of $\mathrm{CMV}^{28}$. All of these effects increase the cost of care after transplantation.

Classically, because of its high rate of CMV primary infection, concern was mainly focused in CMV 
Table 1. Distribution of subjects carrying at least one given HLA allele in the whole population and response against CMV gH ELISA (Ref. 25)

\begin{tabular}{|c|c|c|c|c|c|}
\hline \multirow{2}{*}{ HLA-DR } & \multirow{2}{*}{$\begin{array}{c}\text { Whole } \\
\text { population } \\
(N=471) \\
\text { No. }(\%)\end{array}$} & \multicolumn{2}{|c|}{$\begin{array}{c}\text { Response against gH ELISA } \\
\text { No.(\%) }\end{array}$} & \multirow{2}{*}{ Odds ratio } & \multirow{2}{*}{$95 \%$ C.I. } \\
\hline & & $\begin{array}{l}\text { positive } \\
(N=404)\end{array}$ & $\begin{array}{l}\text { Negative } \\
(N=67)\end{array}$ & & \\
\hline 1 & $50(10.6)$ & $45(11.1)$ & $5(7.5)$ & 1.51 & $0.59-3.88$ \\
\hline 4 & $226(48.0)$ & $193(47.8)$ & $33(49.3)$ & 0.95 & $0.61-1.46$ \\
\hline 8 & 91(19.3) & $79(19.6)$ & 12(17.9) & 1.09 & $0.57-2.07$ \\
\hline 9 & $95(20.2)$ & $87(21.5)$ & 8(11.9) & 1.89 & $0.89-4.01$ \\
\hline 10 & $11(2.3)$ & $5(1.2)$ & $6(9.0)$ & 0.13 & $0.04-0.44$ \\
\hline 11 & $24(5.1)$ & $17(4.2)$ & $5(7.5)$ & 0.38 & $0.15-0.95$ \\
\hline 12 & $48(10.2)$ & $41(10.1)$ & $7(10.4)$ & 0.96 & $0.42-2.19$ \\
\hline 13 & $58(12.3)$ & $48(11.9)$ & $10(14.9)$ & 0.77 & $0.38-1.57$ \\
\hline 14 & $100(21.2)$ & $88(21.8)$ & 12(17.9) & 1.23 & $0.65-2.33$ \\
\hline 15 & $148(31.4)$ & $127(31.4)$ & 21(31.3) & 0.99 & $0.60-1.65$ \\
\hline 16 & $9(1.9)$ & 7(1.7) & $2(3.0)$ & 0.57 & $0.12-2.78$ \\
\hline
\end{tabular}

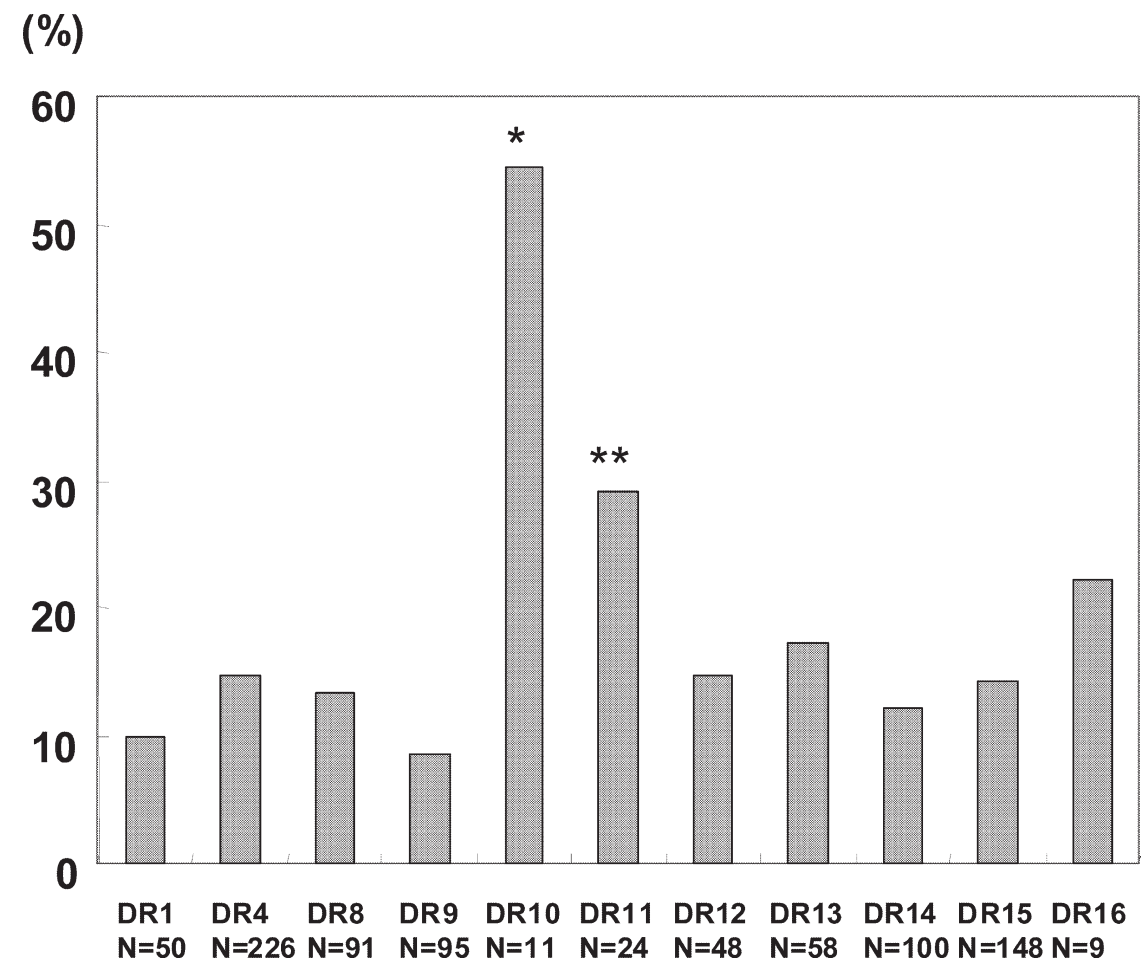

Fig. 4. Percentages of serum samples which had no response against CMV gH ELISA in each HLA type subpopulation. *Subjects with HLA-DR10 showed significantly lower response rate against gH ELISA compared with subjects with HLA-DR1, DR4, DR8, DR9, DR12, DR13 DR14 and DR15. **Subjects with HLA-DR11 showed significantly lower response rate compared with subjects with HLA-DR1, DR9 and DR14. (Ref. 25).

$\mathrm{D}+/ \mathrm{R}-$ transplantation. However, in the $\mathrm{D}+/ \mathrm{R}+$ transplantation, the presence of antibodies against matched CMV gH epitopes had influences to the outcome of transplantation. More adverse event was observed in the case of reinfection of different
CMV strain.

Classification of patients according to $\mathrm{CMV}$ gH antibody responses

On the basis of the combinations of antibody 
responses against the strain-specific gH epitopes, the conventional $\mathrm{CMV} \mathrm{D}+/ \mathrm{R}+$ pairings are classified into two groups. When a recipient received an organ graft from a donor who has the same strainspecific gH antibody of CMV as the recipient, the pairing classified as 'matched gH' pairing. The pairings that the recipients do not have the strain-specific $\mathrm{gH}$ antibodies which matched to their donor's are classified as 'mismatched $\mathrm{gH}$ ' pairings. Our data which analysed 101 pairings of renal transplantation showed the differences among the $\mathrm{D}+/ \mathrm{R}-$, matched $\mathrm{gH}$ and mismatched $\mathrm{gH}$ pairings in the clinical course after renal transplantation.

\section{CMV disease and antigenemia}

The data which analyzed consecutive $77 \mathrm{D}+/$ $\mathrm{R}+$ transplant recipients showed that the recipients in the $\mathrm{gH}$-matched group were more likely to be protected from CMV disease compared with those in the $\mathrm{gH}$-mismatched group or $\mathrm{D}+/ \mathrm{R}-$ group (Table 2). Although statistical differences in the incidence of CMV infection were not observed, CMV disease was significantly more prevalent in the mismatched group than in the matched group. The proportion of cases of CMV infection that progressed to CMV disease in the strain-specific antibody-mismatched and antibody-matched groups were $64 \%$ and $17 \%$, respectively $(P=0.0038)$. Among the $\mathrm{D}+/ \mathrm{R}-$ pairs, $67 \%$ of recipients had CMV infection, and $54 \%$ of them developed CMV disease.

The maximum numbers of pp65-positive cells obtained during the follow up antigenemia assay after renal transplantation are plotted in Figure 5. The difference in the maximum positive cell numbers in the $\mathrm{gH}$ antibody-matched group was statistically significant compared with $\mathrm{gH}$ antibodymismatched group and $\mathrm{D}+/ \mathrm{R}-$ group. These findings indicate the relationship between the degree of neutralization and outcome of transplantation in the $\mathrm{D}+/ \mathrm{R}+$ setting. In addition to the $\mathrm{gH}$ antibody, the absence of antibody responses against gB AD2 can be a good indicator for CMV disease ${ }^{29)}$.

CMV strain-specific ELISA can reveal the strain-specific sero-status and it also allow us to estimate the type of CMV glycoprotein $\mathrm{H}$ persisting in the subject. The nucleotide sequence of the region of the glycoprotein $\mathrm{H}$ epitope in the CMV-DNA extracted from the transplant recipients who showed high degree of antigenemia during the follow up revealed that CMV strains causing infection were of donor origin (Table 3 ).

The combination of strain-specific CMV-gH antibody responses in transplant donors and recipient can predict the possibility of CMV reinfection after transplantation. The high degrees of antigenemia and high incidences of CMV disease are more prevalent in the case of reinfection of CMV after transplantation.

\section{Acute rejection and CMV serostatus}

The indirect CMV effects result in organ injury and damage. Several studies have implicated CMV in acute rejection after renal transplantation. A large retrospective study of renal and pancreas-renal transplantation found that the risk of renal allograft loss was increased in the presence of CMV disease $^{5)}$. A prospective study of 106 renal transplant recipients concluded that CMV disease, but not asymptomatic CMV infection, was independently associated with biopsy-proven acute allograft rejec$\operatorname{tion}^{30)}$.

Classically, renal allografts in $\mathrm{D}+/ \mathrm{R}-$ settings were considered to be at higher risk of acute rejection and graft loss ${ }^{31}$. However, some of the recipients in the conventionally classified $\mathrm{D}+/ \mathrm{R}+$ pairings experience different outcomes after transplantation than was expected according to CMV gH strain-specific antibody matching. The occurrence of acute rejection after transplantation are prevalent in the cases of $\mathrm{D}+/ \mathrm{R}+$ transplantation with mismatched gH antibodies (Figure 6) ${ }^{21}$. The reason why the incidence of acute rejection in the mismatched $\mathrm{gH}$

Table 2. CMV infection and CMV disease after renal transplantation (Ref. 21)

\begin{tabular}{|c|c|c|c|c|}
\hline \multirow{2}{*}{$\begin{array}{c}\text { CMV status/ } \\
\text { strain-specific Ab status }\end{array}$} & \multicolumn{2}{|c|}{$\mathrm{D}+/ \mathrm{R}+$} & \multirow{2}{*}{$\mathrm{D}+/ \mathrm{R}-$} & \multirow{2}{*}{ total } \\
\hline & matched & mismatched & & \\
\hline No. of patients & 45 & 32 & 24 & 101 \\
\hline $\begin{array}{l}\text { Mean weeks (range) of the initial } \\
\text { antigenemia detection }\end{array}$ & $7(1-20)$ & $7(4-13)$ & $8(1-20)$ & $7(1-20)$ \\
\hline No.(\%) of positive antigenemia & $23(51)$ & $14(44)$ & $16(67)$ & $53(52)$ \\
\hline No.(\%) of CMV disease & $4(9)$ & $9(28)^{\mathrm{a}}$ & $13(54)^{\mathrm{b}}$ & $26(26)$ \\
\hline
\end{tabular}

${ }^{\mathrm{a}} p=0.026$ vs. matched, ${ }^{\mathrm{b}} p=0.0008$ vs. matched 


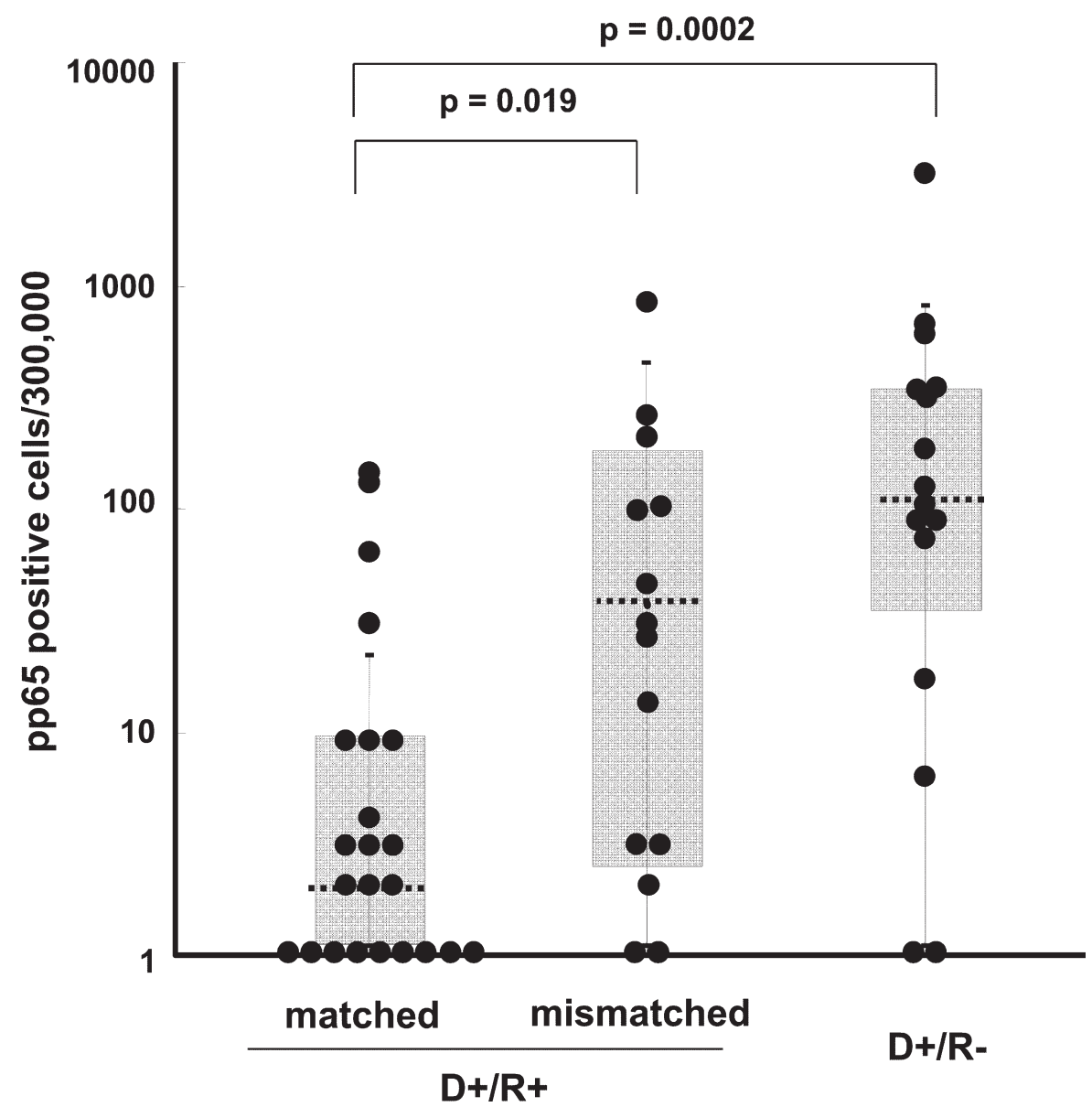

Fig. 5. Antigenemia in the transplant recipients. Maximum number of pp65-positive cells during the monitoring period (6 months) for each recipient with CMV infection was plotted. The broken bars in the box plot indicate the median of the pp65-positive cells. (Ref. 21)

Table 3. Strain-specific antibody responses and amino acid sequences of CMV glycoprotein H (Ref. 23)

\begin{tabular}{|c|c|c|c|c|c|c|c|c|}
\hline \multirow{2}{*}{$\begin{array}{l}\text { Patient } \\
\text { No. }\end{array}$} & \multicolumn{2}{|c|}{$\begin{array}{l}\text { ELISA against } \mathrm{CMV} \mathrm{gH} \\
\text { before transplantation }\end{array}$} & \multirow{2}{*}{$\begin{array}{l}\text { Strain- } \\
\text { specific } \\
\text { antibodies of } \\
\text { recipients } 6 \mathrm{M} \\
\text { after trans- } \\
\text { plantation }\end{array}$} & \multirow{2}{*}{$\begin{array}{l}\text { Weeks of } \\
\text { the CMV } \\
\text { viremia } \\
\text { after } \\
\text { transplan- } \\
\text { tation }\end{array}$} & \multirow{2}{*}{\multicolumn{3}{|c|}{$\begin{array}{l}\text { A.A sequence of PCR product from peripheral blood } \\
\text { samples, type of gH and number of TA clone }(\%)\end{array}$}} & \multirow{2}{*}{$\begin{array}{l}\text { Acquired } \\
\text { CMV } \\
\text { strain after } \\
\text { transplanta- } \\
\text { tion }\end{array}$} \\
\hline & Donor & Recipient & & & & & & \\
\hline 1 & AD169 & negative & AD169 & $6-7$ & SEALDPHAFHLLLN & AD169 & $11(100)$ & AD169 \\
\hline 2 & Towne & negative & Towne & $7-8$ & SEPLD*KAFHLLLN & Towne & $10(100)$ & Towne \\
\hline 3 & AD169 & Towne & $\begin{array}{l}\text { AD169 and } \\
\text { Towne }\end{array}$ & $8-10$ & SEALDPHAFHLLLN & AD169 & $17(100)$ & AD169 \\
\hline 4 & AD169 & Towne & $\begin{array}{l}\text { AD169 and } \\
\text { Towne }\end{array}$ & $7-8$ & $\begin{array}{l}\text { SEALDPHAFHLLLN } \\
\text { SEPLD*KAFHLLLN }\end{array}$ & $\begin{array}{l}\text { AD169 } \\
\text { Towne }\end{array}$ & $\begin{array}{r}10(67) \\
5(33)\end{array}$ & AD169 \\
\hline 5 & $\begin{array}{l}\mathrm{AD} 169 \text { and } \\
\text { Towne }\end{array}$ & AD169 & $\begin{array}{l}\mathrm{AD} 169 \text { and } \\
\text { Towne }\end{array}$ & 10 & $\begin{array}{l}\text { SEALDPHAFHLLLN } \\
\text { SEPLD*KAFHLLLN }\end{array}$ & $\begin{array}{l}\text { AD169 } \\
\text { Towne }\end{array}$ & $\begin{array}{r}11(69) \\
5(31)\end{array}$ & Towne \\
\hline
\end{tabular}

antibody group has been higher than that observed in the matched group is not entirely clear. It is possible that acute rejection is the consequence of strong recipient-derived cytotoxic $\mathrm{T}$ lymphocyte responses against ongoing CMV activities that had escaped humoral responses. Lack of CMV specific memory $\mathrm{T}$ cells may contribute to the lower rate of acute rejection in $\mathrm{D}+/ \mathrm{R}-$ setting. 
B

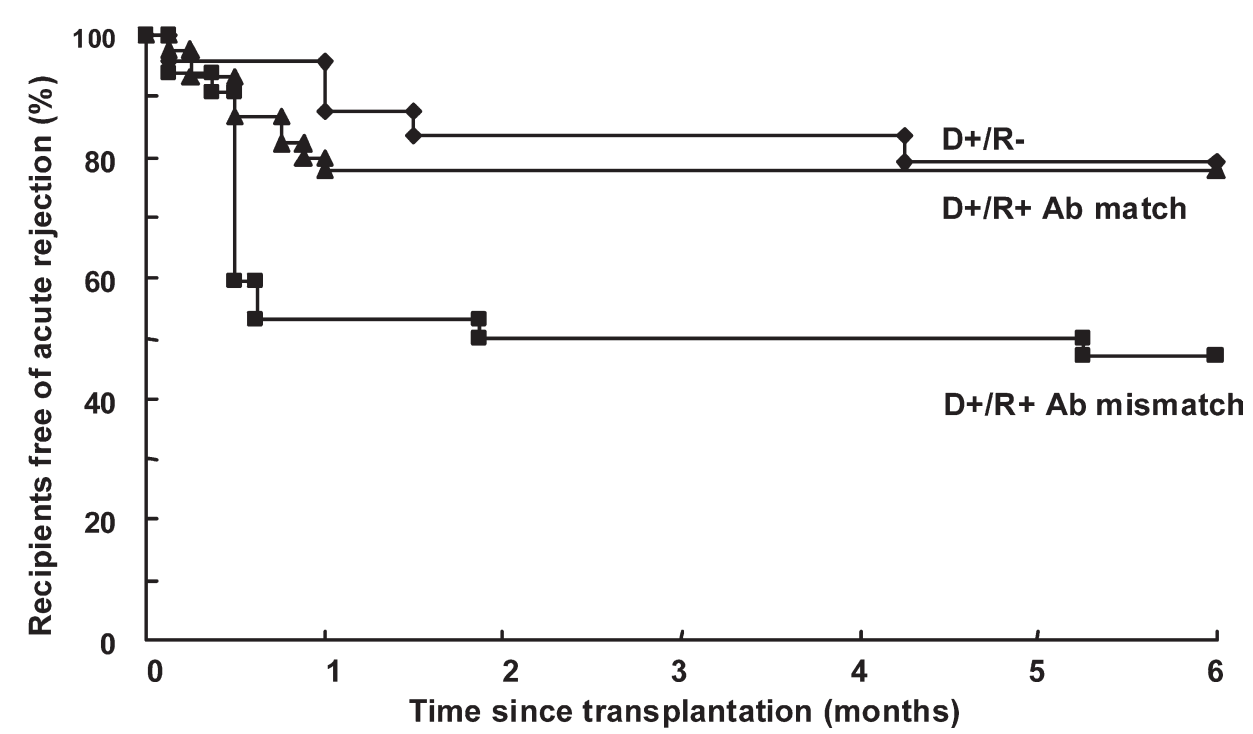

Fig. 6. (A) Summary of incidences of acute rejection. a $p=0.014$ vs. mismatched, $\mathrm{b} p=0.0051$ vs. mismatched (B) Kaplan-Meier curves for the cumulative probability of freedom from biopsy-proven acute rejection. The incidence of acute rejection in the CMV strain-specific antibody mismatched group was significantly higher than those in the $\mathrm{D}+/ \mathrm{R}-$ and strain-specific antibody matched group $(p=0.002)$. (Ref.21)

Prophylaxis strategies, rather than preemptive therapies, can have efficacy on preventing CMV indirect effect. Kleim et $a l .{ }^{32)}$ reported that universal CMV prophylaxis with oral gancyclovir improved long-term renal graft survival compared with preemptive therapy. The most significant effect was observed in $\mathrm{D}+/ \mathrm{R}+$ subgroup. The recipients of the $\mathrm{D}+/ \mathrm{R}+$ group with $\mathrm{gH}$ mismatch antibodies are most likely to have benefits of CMV prophylaxis strategy.

\section{CONCLUSION}

Among the CMV D $+/ \mathrm{R}+$ renal transplant recipients, more adverse events were observed when the CMV gH antibodies were mismatched, indicating that reinfection with a different CMV strain may increase complications. The ELISA using the antigens of recombinant $\mathrm{gH}$ and $\mathrm{gB}$ will provide useful information regarding antibody responses against $\mathrm{CMV}$, predicting CMV reinfection.

\section{ACKNOWLEDGEMENT}

This work was supported by a Grant-in-Aid for Scientific Research from the Japan Society for the Promotion of Science (No. 16591609) and a grant from the Fukushima Society for the Promotion of Medicine.

\section{CONFLICT OF INTEREST STATEMENT}

No authors have any conflicts of interest to declare.

\section{REFERENCES}

1. Meier-Kriesche HU, Schold JD, Srinivas TR and 
Kaplan B. Lack of improvement in renal allograft survival despite a marked decrease in acute rejection rates over the most recent era. Am J Transplant, 4 : 378-383, 2004.

2. Lautenschlager I, Soots A, Krogerus L, Kauppinen H, Saarinen O, Bruggeman C and Ahonen J. Effect of cytomegalovirus on an experimental model of chronic renal allograft rejection under tripledrug treatment in the rat. Transplantation, 64 : 391-398, 1997.

3. Humar A, Gillingham KJ, Payne WD, Dunn DL, Sutherland DE and Matas AJ. Association between cytomegalovirus disease and chronic rejection in kidney transplant recipients. Transplantation, 68 : 1879-1883, 1999.

4. McLaughlin K, Wu C, Fick G, Muirhead N, Hollomby D and Jevnikar A. Cytomegalovirus seromismatching increases the risk of acute renal allograft rejection. Transplantation, 74: 813-816, 2002.

5. Nett PC, Heisey DM, Fernandez LA, Sollinger HW and Pirsch JD. Association of cytomegalovirus disease and acute rejection with graft loss in kidney transplantation. Transplantation, 78: 10361041, 2004.

6. Schnitzler MA, Woodward RS, Brennan DC, Spitznagel EL, Dunagan WC and Bailey TC. Impact of cytomegalovirus serology on graft survival in living related kidney transplantation: implications for donor selection. Surgery, 121 : 563-568, 1997.

7. Schnitzler MA, Woodward RS, Brennan DC, Spitznagel EL, Dunagan WC and Bailey TC. The effects of cytomegalovirus serology on graft and recipient survival in cadaveric renal transplantation : implications for organ allocation. Am J Kidney Dis, 29 : 428-434, 1997.

8. Larsson S, Soderberg-Naucler C and Moller E. Productive cytomegalovirus (CMV) infection exclusively in CD13-positive peripheral blood mononuclear cells from CMV-infected individuals : implications for prevention of CMV transmission. Transplantation, 65 : 411-415, 1998.

9. Egli A, Binggeli S, Bodaghi S, Dumoulin A, Funk GA, Khanna N, Leuenberger D, Gosert R and Hirsch HH. Cytomegalovirus and polyomavirus BK posttransplant. Nephrol Dial Transplant, 22 Suppl 8 : viii72-viii82, 2007.

10. Britt WJ and Mach M. Human cytomegalovirus glycoproteins. Intervirology, 39 : 401-412, 1996.

11. Keay $\mathrm{S}$ and Baldwin B. Anti-idiotype antibodies that mimic gp86 of human cytomegalovirus inhibit viral fusion but not attachment. J Virol, 65 : 5124-5128, 1991.

12. Hobom U, Brune W, Messerle M, Hahn G and Koszinowski UH. Fast screening procedures for random transposon libraries of cloned herpesvirus genomes : mutational analysis of human cytomegalovirus envelope glycoprotein genes. J Virol, 74: 7720-7729, 2000.

13. Urban M, Klein M, Britt WJ, Hassfurther E and Mach M. Glycoprotein H of human cytomegalovirus is a major antigen for the neutralizing humoral immune response. J Gen Virol, 77(Pt 7) : 15371547, 1996.

14. Chou S. Molecular epidemiology of envelope glycoprotein $\mathrm{H}$ of human cytomegalovirus. J Infect Dis, 166 : 604-607, 1992.

15. Boppana SB, Rivera LB, Fowler KB, Mach M and Britt WJ. Intrauterine transmission of cytomegalovirus to infants of women with preconceptional immunity. N Engl J Med, 344 : 1366-1371, 2001.

16. Meyer H, Sundqvist VA, Pereira L and Mach M. Glycoprotein gp116 of human cytomegalovirus contains epitopes for strain-common and strainspecific antibodies. J Gen Virol, 73(Pt 9) : 23752383, 1992.

17. Ohlin M, Sundqvist VA, Mach M, Wahren B and Borrebaeck CA. Fine specificity of the human immune response to the major neutralization epitopes expressed on cytomegalovirus gp58/116 (gB), as determined with human monoclonal antibodies. J Virol, 67 : 703-710, 1993.

18. Schoppel K, Hassfurther E, Britt W, Ohlin M, Borrebaeck CA and Mach M. Antibodies specific for the antigenic domain 1 of glycoprotein B (gpUL55) of human cytomegalovirus bind to different substructures. Virology, 216 : 133-145, 1996.

19. Fowler KB, Stagno $S$ and Pass RF. Maternal immunity and prevention of congenital cytomegalovirus infection. Jama, 289 : 1008-1011, 2003.

20. Lagasse N, Dhooge I and Govaert P. Congenital CMV-infection and hearing loss. Acta Otorhinolaryngol Belg, 54 : 431-436, 2000.

21. Ishibashi K, Tokumoto T, Tanabe K, Shirakawa H, Hashimoto K, Kushida N, Yanagida T, Inoue N, Yamaguchi O, Toma $\mathrm{H}$ et al. Association of the outcome of renal transplantation with antibody response to cytomegalovirus strain-specific glycoprotein $\mathrm{H}$ epitopes. Clin Infect Dis, 45: 60-67, 2007.

22. Klein M, Schoppel K, Amvrossiadis N and Mach M. Strain-specific neutralization of human cytomegalovirus isolates by human sera. J Virol, 73 : 878-886, 1999.

23. Ishibashi K, Tokumoto T, Shirakawa H, Hashimoto K, Kushida N, Yanagida T, Shishido K, Aikawa K, Yamaguchi O, Toma $\mathrm{H}$ et al. Strain-specific seroepidemiology and reinfection of cytomegalovirus. Microbes Infect, 10 : 1363-1369, 2008.

24. Wada K, Mizuno S, Ohta H and Nishiyama Y. Immune response to neutralizing epitope on human cytomegalovirus gylcoprotein B in Japa- 
nese : correlation of serologic response with HLA-type. Microbiol Immunol, 41: 841-845, 1997.

25. Ishibashi K, Tokumoto T, Shirakawa H, Hashimoto K, Kushida N, Yanagida T, Shishido K, Aikawa K, Yamaguchi O, Toma $\mathrm{H}$ et al. Association between antibody response against cytomegalovirus strainspecific glycoprotein $\mathrm{H}$ epitopes and HLADR. Microbiol Immunol, 53 : 412-416, 2009.

26. Retiere C, Lesimple B, Lepelletier D, Bignon JD, Hallet MM and Imbert-Marcille BM. Association of glycoprotein B and immediate early-1 genotypes with human leukocyte antigen alleles in renal transplant recipients with cytomegalovirus infection. Transplantation, 75 : 161-165, 2003.

27. Fan J, Meng XQ, Yang MF, Zhou L, Chen XM, Hu MJ, Fan WW, Ma WH and Li LJ. Association of cytomegalovirus infection with human leukocyte antigen genotypes in recipients after allogeneic liver transplantation. Hepatobiliary Pancreat Dis Int, 5 : 34-38, 2006.

28. Ljungman P, Griffiths P and Paya C. Definitions of cytomegalovirus infection and disease in transplant recipients. Clin Infect Dis, 34 : 1094-1097, 2002.

29. Ishibashi K, Tokumoto T, Shirakawa H, Hashimoto
K, Ikuta K, Kushida N, Yanagida T, Shishido K, Aikawa K, Toma $\mathrm{H}$ et al. Lack of antibodies against the antigen domain 2 epitope of cytomegalovirus (CMV) glycoprotein B is associated with CMV disease after renal transplantation in recipients having the same glycoprotein $\mathrm{H}$ serotypes as their donors. Transpl Infect Dis. 2010 Aug 30. [Epub ahead of print]

30. Reischig T, Jindra P, Svecova M, Kormunda S, Opatrny K, Jr. and Treska V. The impact of cytomegalovirus disease and asymptomatic infection on acute renal allograft rejection. J Clin Virol, 36 : 146-151, 2006.

31. McLaughlin K, Sandhu S, Wu C, Muirhead N, Hollomby D and Jevnikar A. Transplanting kidneys from CMV-seropositive donors to CMVseronegative recipients is not associated with poorer renal allograft function or survival. Nephrol Dial Transplant, 20 : 176-180, 2005.

32. Kliem V, Fricke L, Wollbrink T, Burg M, Radermacher $\mathrm{J}$ and Rohde $\mathrm{F}$. Improvement in long-term renal graft survival due to CMV prophylaxis with oral ganciclovir : results of a randomized clinical trial. Am J Transplant, 8 : 975-983, 2008. 